\title{
Editorial: The Baltic Sea Region in Transition
}

\author{
Marcus Reckermann ${ }^{1 *}$, H.E. Markus Meier ${ }^{2}$ and Martin Stendel ${ }^{3}$ \\ ${ }^{1}$ International Baltic Earth Secretariat, Helmholtz Centre for Materials and Coastal Research (HZG), Geesthacht, Germany, \\ ${ }^{2}$ Leibniz Institute for Baltic Sea Research Warnemünde, Rostock, Germany, ${ }^{3}$ Danish Meteorological Institute (DMI), Copenhagen, \\ Denmark
}

Keywords: Baltic Sea, Baltic Earth, Earth system, climate change, coastal research

Editorial on the Research Topic

\section{The Baltic Sea Region in Transition}

The Baltic Sea is a semi-enclosed sea in Northern Europe, draining about 20\% of Europe in its catchment area, where about 85 Million people live; most of them in the southern part. The region and the Baltic Sea itself have been subject of interdisciplinary Earth system research for many decades, and especially so since the barriers between the eastern and western researchers fell in the early 1990. Baltic Earth and its precursor program BALTEX have fostered the collaboration of Earth system research across the countries and scientific disciplines for almost 30 years, also as part of the global GEWEX(Global Energy and Water Exchanges) program of WCRP, the World Climate Research Program of WMO, the World Meteorological Organization.

This Frontiers Research Topic in Frontiers is based on contributions from the 2nd Baltic Earth Conference in Helsingør, June 11-15, 2018. Like the previous Baltic Earth and BALTEX conferences (nine in total), it covered the themes of Baltic Earth, in particular highlighting the Baltic Earth Grand Challenges as defined by the Baltic Earth Science Plan 2017. The grand topic of the conference "The Baltic Sea region in transition" refers both to processes in the transition area between the North Sea and the Baltic Sea, but more so to temporal transition processes (e.g., regional climate change) in the energy, water and matter cycles of the Baltic Sea, its coasts, the atmosphere, land surface and socioeconomic system of its catchment basin. At this conference, the Grand Challenges and research topics of the science plan were discussed within the following sessions:

- Salinity dynamics

- Land-Sea-Atmosphere biogeochemical feedbacks

- Natural hazards and high impact events

- Sea level dynamics, coastal morphology and erosion

- Regional variability of water and energy exchanges

- Multiple drivers of regional Earth system changes

- Regional climate system modeling

The 19 contributions in this Frontiers Research Topic are part of the 126 which were presented orally or as posters at the conference in Denmark (all available as extended abstracts), spanning the spectrum of Baltic Earth research, from observed and modeled processes in the atmosphere, the sea and on land, as well as transition processes between these compartments. Innovative methods and management issues were also discussed. In the following, we briefly introduce the papers of this Research Topic.

Quite a number of papers treated oceanographic issues. Salinity distribution is crucial for the vertical stratification of the water column, and to a large extent controls the distribution of organisms, from bacteria to fish. Liblik and Lips have analyzed 35 years of Baltic Sea 
observational data and conclude that stratification, which is basically dependent on the distribution of salinity and temperature in the water column, and which is peculiar in the Baltic Sea, has increased over this period. While there was a clear warming trend in the water column (about twice as much as in the upper Atlantic), they found different salinity trends in different depth layers, causing an overall increase in stratification but no significant trend in mean salinity of the Baltic Sea.

The generation and distribution of internal waves in the Baltic Sea, which plays a role also in stratification and mixing, is investigated by Kurkin et al. Using a circulation model, they analyze the main properties of long-period subinertial baroclinic motions in the Baltic Sea, focusing on periods in the range of 2-12 days. Results suggest that the relevant field of motions in the Baltic Sea is highly inhomogeneous and strongly asymmetric.

A way to overcome the limitation of very few real sampling (data) points at sea, is to combine measured with modeled data. Elken et al. present a statistical method to reconstruct temperature and salinity data from measurements and models. For Sea Surface Temperature, their Empirical Orthogonal Functions method perform better than a similar technique (Optimal Interpolation), which is slightly better for Sea Surface Salinity. The authors claim that their Empirical Orthogonal Functions has certain advantages when real observations are very sparse.

The measurement of real field data to give insight into the distribution and velocity of water bodies in the Baltic Sea necessary to validate models. Paka et al. describe a new method for vertical profiling the water column, especially in the difficult narrow bottom layer. Using this new profiling method, some remarkable temperature and current velocities were measured in the deep water.

In the northern Baltic Sea, sea ice is a common feature in winter. Sea ice cover has a strong impact on the wave climate of adjacent sea areas, and consequently, on operational wave forecasting. Using wave models, Tuomi et al. compared two data sources and two methods to calculate significant wave heights. The results can help to optimize operational wave forecasts in the northern Baltic Sea in winter.

Good measurements of methane fluxes are crucial for climate models, as methane is a much more potent greenhouse gas than $\mathrm{CO}_{2}$, albeit present in much lower concentrations. GutiérrezLoza et al. present a method to measure air-sea methane fluxes. They demonstrate that high-resolution micro-meteorological techniques can increase the understanding of the temporal variability and forcing processes of these fluxes, and thus improve the capability of climate models to incorporate them.

Rapid methodological innovations and developments are currently ongoing in Baltic Sea Operational Oceanography. In this review paper, She et al. introduce two large research networks in the Baltic Sea, which both work complimentary on scientific questions: BOOS (Baltic Sea Operational Oceanographic System) and Baltic Earth (formerly BALTEX). Both are different in their scientific scope but have the potential to significantly improve Baltic Sea oceanographic research in terms of operational measurements and model applicability and quality.
Sea level change and variability in the Baltic Sea is a quite complicated issue, due to the geological and meteorological situation of the Baltic Sea. There are not many sea level projections for the Baltic Sea. Madsen et al. (a) have calculated sea level trends and variabilities from statistical reconstructions (i.e., statistical treatments of monthly tide gauge measurements and re-analyses) and compared this with satellite altimetry. Generally, the results for the trends are comparable to global estimates.

Together with other collaborators, Madsen also performed an investigation on stakeholder needs concerning sea level change in Denmark (Madsen et al. (b)). Aim of the study is to map user needs of coastal municipalities, which are responsible for coastal protection. The study indicates the need for good storm surge warnings, extreme sea levels and wave heights. Common scenarios are needed to help the collaboration between municipalities.

Using different statistical methods, Medvedev et al. investigated the strong variability of Baltic Sea sea levels over different periods. The study demonstrates the strong influence of zonal wind variations, i.e., regional meteorological conditions, on the low-frequency sea level variability of the Baltic Sea.

Hydrology describes the transfer of water between the ocean, the atmosphere and the land surface including rivers and lakes. It is a crucial element in the global climate system, and is has been studied thoroughly in the Baltic Sea region. Coupled regional models are used to incorporate the water cycle into regional and global climate models, but to a rather unsatisfying degree. Hagemann et al. have further developed a hydrological model system to a very high temporal and spatial resolution, which can closely simulate the terrestrial hydrological cycle (discharge) in the climate model. However, human modifications to the water cycle (river regulations, dams) are not accounted for, making it difficult to model the discharge in many heavily regulated Scandinavian subbasins.

Two contributions deal with the hydrological conditions in the Russian sub-catchment of the river Dvina/Daugava. Terskii et al. provide a new assessment of the water cycle components in the catchment, using open source data and a hydrological model. The developed modeling approach can be used to assess water resources, climate change impacts and water quality issues.

In the same sub-catchment of the Russian part of the Dvina River, Danilovich et al. analyze past changes in climate and steam flow and projected future changes, using historical runoff data and different models using two representative concentration pathways scenarios. A positive monthly trend for stream flow for the past was found for December to April, but not for the rest of the year. For the future until the end of the century, a clear warming and stronger precipitation is projected, and runoff during the low-flow period in winter is expected to increase considerably.

Two papers investigate the impact of atmospheric circulation on temperature and droughts in the Baltic and Black Sea regions. Parts of the Baltic region, e.g., Estonia, have received stronger warming than the global average. Lakson et al. investigated the impact of atmospheric circulation on this exceptional warming, and they conclude that a higher frequency of certain circulation 
types is probably not responsible for the warming, but rather a warming within circulation types.

The frequency of droughts and dry winds in the recent past was studied by Semenova et al. in the steppe region of southern Ukraine, in the catchment of the Black Sea. They found that during the two last decades, the Black Sea steppe province was characterized by a significant increasing frequency of droughts and dry winds, which is considered a problem for this agriculturally important region.

Regional climate models need to be validated with real measured observational data, which are quite heterogeneous in space and time. In order to serve as a validation reference, the input data for these data sets have to be homogenized with respect to quality as well as spatial and temporal dimensions. Hinrichs et al. have developed a new, comprehensive observation-based data product of both atmospheric and hydrographic parameters for the North Sea and Baltic Sea, for the period 1950-2015. The dataset is freely available on the institutional website.

Regional climate models can be coupled with biogeochemical and ecosystem models to estimate the impact of climate change on ecosystems and help with suitable management decisions. Uncertainties are intrinsic factors in regional and the driving global climate models, and more so in ecosystem models. Saraiva et al. have analyzed uncertainties in a coupled physicalbiogeochemical Baltic Sea model (simulating nutrient loads, biogeochemical fluxes and oxygen conditions), forced by a regional climate model and driven by global climate models. The components have their own uncertainties, and it was found that the uncertainties related to the nutrient load scenarios are larger than those of the climate models and greenhouse gas scenarios. Substantial uncertainties of future projections for the Baltic Sea are caused by the driving global climate models, but it was nevertheless concluded that nutrient abatement measures implemented (the so-called Baltic Sea Action Plan) would significantly improve the ecosystem state.

Eutrophication, i.e., the surplus nutrition in an ecosystem, is subject of the last two papers presented here. Changes in nutrient concentrations over 20 years and their relation to coastal freshwater sources at the German Baltic Sea coast was analyzed by Kuss et al., by using a novel approach to correlate nutrient concentrations with salinity measurements. The authors show that nutrient concentrations in the freshwater have mostly decreased over the analyzed period.

Finally, Ivarsson et al. present a history of eutrophication for some sites on the Swedish east coast, based on sediment samples. They estimate the onset of anthropogenic eutrophication in the area to between 1800 and $1900 \mathrm{CE}$, depending on the sampling site. They did not find evidence that the extensive oxygen depletion during the Medieval Climate Anomaly was caused by human activities.

We believe that this compilation of research papers represents a good overview over the currently ongoing Earth system research activities in the Baltic Sea region, providing new insights for the scientific community.

\section{AUTHOR CONTRIBUTIONS}

All authors listed have made a substantial, direct and intellectual contribution to the work, and approved it for publication.

\section{ACKNOWLEDGMENTS}

We thank all authors for their valuable contribution to this Research Topic, and to all participants of the 2nd Baltic Earth Conference in Helsingor, Denmark.

Conflict of Interest: The authors declare that the research was conducted in the absence of any commercial or financial relationships that could be construed as a potential conflict of interest.

Copyright $\odot 2020$ Reckermann, Meier and Stendel. This is an open-access article distributed under the terms of the Creative Commons Attribution License (CC BY). The use, distribution or reproduction in other forums is permitted, provided the original author(s) and the copyright owner(s) are credited and that the original publication in this journal is cited, in accordance with accepted academic practice. No use, distribution or reproduction is permitted which does not comply with these terms. 